\title{
EPISTEMOLOGIA AMBIENTAL: A crise ambiental como uma crise da razão
}

\author{
Matheus Silva De Gregori ${ }^{1}$ \\ Luiz Ernani Bonesso de Araujo ${ }^{2}$
}

\begin{abstract}
Resumo: O presente estudo tem como objetivo analisar a crise do meio ambiente sob uma abordagem epistemológica, ou seja, a partir do conhecimento produzido em relação à natureza. Verifica-se que o pensamento ocidental, manifestado pelos paradigmas da Ciência Moderna, está ligado à organização dos sistemas econômicos que reconheceram historicamente a natureza apenas como recurso e potencial de produção de capital, vindo a encontrar, por esta via, o limite entrópico da biosfera e, por conseguinte, do crescimento. Abordou-se o processo de construção do conhecimento, questionando-se a possibilidade de concepção de outras perspectivas, fundadas na inseparabilidade entre sujeito-objeto, ação-pensamento e homem-natureza. É percebida a necessidade do ser humano de se re-significar no mundo, conhecendo a complexidade da natureza e pensando além da crise ecológica.
\end{abstract}

Palavras-chave: Epistemologia. Ecologia. Crise.

\section{ASPECTOS INTRODUTÓRIOS}

O problema da (in)sustentabilidade, associado às constatações de que o meio ambiente esteja chegando ao seu limite, tem se apresentado como a crise do nosso tempo. A abordagem do tema como o desafio da nossa época tem gerado as mais diversas estratégias de gerenciamento do risco ambiental. Em algumas se nota certa efetividade e impacto positivo na sociedade, como as políticas públicas de preservação da natureza. Observa-se também, por outro lado, determinados desvios oportunistas, sustentados por uma publicidade favorável, podendo ser aludidos pelo movimento empresarial conhecido como "capitalismo verde".

Independentemente das diversas direções que os movimentos ligados ao meio ambiente tomaram, mostra-se adequado, antes de sopesar a ação mais favorável, analisar como a estratégia foi estabelecida, bem como, ainda antes, como o contexto de crise foi deflagrado. Neste sentido, o presente trabalho pretende abordar o processo que gerou a insustentabilidade, bem como os agentes ou modelos econômicos responsáveis,

\footnotetext{
${ }^{1}$ Autor - Acadêmico do $6^{\circ}$ semestre do curso de Direito - Universidade Federal de Santa Maria, participante do Grupo de Pesquisa de Direitos da Sociobiodiversidade - GPDS/UFSM. Bolsista PIBIC/CNPq.

2 Autor/Orientador - Coordenador do Grupo de Pesquisa de Direitos da Sociobiodiversidade GPDS/UFSM. Possui Doutorado em Direito pela UFSC e atualmente é professor da UFSM, com ênfase em Direito Agrário e Ambiental.
} 
Com efeito, a idéia de que o mundo é pré-dado em relação à consciência humana, ou seja, a separação entre sujeito-objeto - ainda que fragilizada pelas descobertas da física quântica e as demais reflexões do séc. XX - representa o "núcleo duro" de toda a ciência ocidental. Esse paradigma considera que o subjetivismo compromete a "pureza” científica, dando-se então privilégio à objetividade, até porque, o mundo existiria "fora" do ser humano, devendo ser por ele internalizado, ou seja, conhecido/estudado e (por que não?) explorado.

Ocorre que a criação do mundo se dá de forma diferente, menos passiva e condicionada como vinha propondo a ciência tradicional, até porque, como aduzem Maturana e Varela (p. 22, 2005), pode-se demonstrar

[...] ao estudar de perto o fenômeno do conhecimento e as ações dele surgidas, que toda experiência cognitiva inclui aquele que conhece de um modo pessoal, enraizado em sua estrutura biológica, motivo pelo qual toda experiência de certeza é um fenômeno cego em relação ao ato cognitivo do outro, numa solidão que só é transcendida no mundo que criamos junto com ele.

Desse modo, ao descobrirmos que toda percepção é construída de acordo com as estruturas internas em que operamos, fica evidente que estamos em constante interação com o mundo que nos cerca, construindo-o e sendo construídos por ele. A noção dessa responsabilidade, ao invés de se apresentar como um encargo, pode ser vista como uma oportunidade de emancipação do pensamento e, por conseguinte, da nossa ação sobre o mundo. De vítimas, ou agentes meramente passivos de uma realidade, nos vemos como autores desta, empoderados na possibilidade de criar novas soluções.

Para vislumbrar essa percepção, é necessário que contemplemos nossa observação, conheçamos a construção do nosso conhecer, para assim confirmar que "aquilo que tomávamos como uma simples captação de algo [...] traz a marca indelével de nossa própria estrutura” (MATURANA, VARELA, p. 27, 2005).

No entanto, vemo-nos tentados pelas justificações do representacionismo, damos as costas à história da ciência, buscando guarida nas certezas que já mostraram ser provisórias. Basicamente, não vemos que não vemos, sendo que os efeitos dessa 


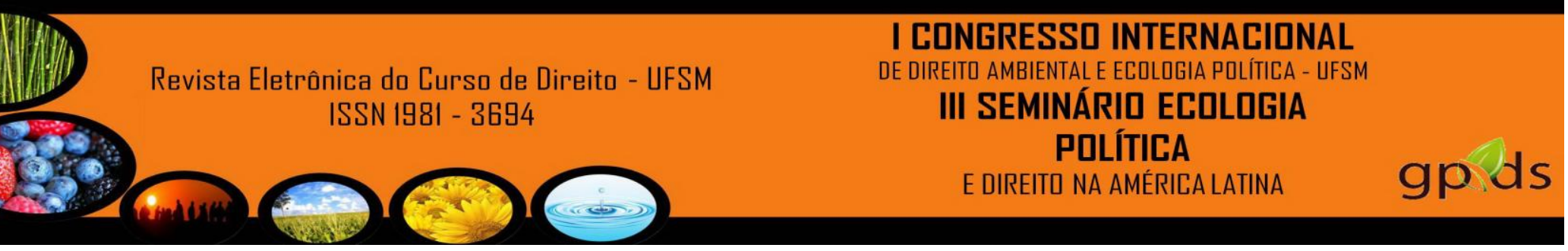

ignorância se apresentam agora como a crise ambiental a ser gerenciada, face ao limite entrópico inevitável imposto pela natureza.

\title{
3. Crise Ambiental
}

As consequiências éticas do pensamento ocidental são óbvias e devastadoras. Fica evidenciado que essa estrutura cognitiva constitui o fundamento da mentalidade predatória que só vê o mundo como recurso a ser explorado pelo homem em busca de benefícios (MATURANA, VARELA, 2005). Quando esse pensamento assume vias de globalização, estabelece-se um cenário propício ao surgimento da crise ambiental.

A idéia de realidade proposta pelas ciências, representadas pelo "projeto positivista”, que estabeleceram a base da organização político-econômica que culmina com o mundo globalizado, apoiava-se na idéia de que o conhecimento seria uma espécie de libertação do homem da ignorância, uma busca pela verdade. Entretanto, como assegura Leff (p. 41, 2003):

\begin{abstract}
A ciência - que se pensava libertadora do atraso e da opressão, do primitivismo e do subdesenvolvimento - gerou um desconhecimento do mundo, um conhecimento que não sabe de si mesmo; que governa um mundo alienado do qual desconhecemos seu conhecimento especializado e as regras do poder que governam.
\end{abstract}

Essa ciência é manifestada na padronização do conhecimento, do método científico, e, respectivamente, do modelo econômico (capitalista) onde tudo é avaliado a partir da medida do quantum econômico que representa. Em outros termos, pode-se dizer que a economização do mundo traduz a realidade nos termos do "valor de mercado", induzindo a globalização do capital como a forma de totalização do ser no mundo (LEFF, 2003).

Afirmam Araújo e Silva (p.141, 2007) que essa visão limitada da realidade

diante de questões multidimensionais, a incapacidade de perceber problemas que parecem distintos, mas que estão conectados e são interdependentes, revela uma visão obsoleta de mundo, uma percepção da realidade inadequada com a respectiva complexidade. Significa uma falta de atenção para observar as múltiplas possibilidades de relações e inter-relações, o que prejudica uma 
adequada contextualização, e conseqüentemente a capacidade de organização de idéias.

As conseqüências desse pensamento se demonstram, por exemplo, na apropriação dos recursos naturais dos países subdesenvolvidos, a desconsideração do valor cultural da biodiversidade e da sabedoria dos povos tradicionais, dentro de uma lógica que só aprecia aquilo que pode ser patenteado e vendido. Neste sentido, é possível citar, por exemplo, a Convenção sobre Diversidade Biológica ${ }^{3}$ (CBD), que foi contraposta pelo Acordo TRIPs ${ }^{4}$, facilitando-se, assim, o controle da dinâmica de mercado pelas grandes corporações e pelos detentores do capital, e legitimando o processo perverso da biopirataria e da etnobioprospecção ${ }^{5}$.

Demonstra-se que a preocupação com o meio ambiente não alcança os níveis sutis do problema, até porque tocam no ponto frágil que legitima toda a lógica do mercado: estamos submersos à ordem do capital, pensamos e agimos de acordo com suas premissas. A notícia alarmante da maximização do Efeito Estufa, o Aquecimento Global e toda a dinâmica dos créditos de carbono ${ }^{6}$ redirecionaram a agenda do século XXI, as estratégias empresariais e o gerenciamento do risco ambiental. Ainda assim, não se verifica uma mudança estrutural, uma substituição de paradigma que possibilite

\footnotetext{
${ }^{3}$ Disponível na íntegra em http://www.onu-brasil.org.br/doc cdb.php. Acesso em 12/07/2012 De modo geral, a CDB propõe regras para garantir a conservação da diversidade biológica, o seu uso sustentável e a justa repartição dos benefícios provenientes da exploração econômica dos recursos genéticos das espécies, respeitada a soberania das nações sobre o patrimônio existente em seu território. Foi criada em 1992, durante a Rio-92, mais conhecida como Conferência das Nações Unidas sobre o Meio Ambiente e o Desenvolvimento (CNUMAD). O seu objetivo principal era buscar meios de conciliar o desenvolvimento sócio-econômico com a conservação e proteção dos ecossistemas da Terra.

${ }^{4} \mathrm{O}$ Acordo TRIPs (do inglês Agreement on Trade-Related Aspects of Intellectual Property Rights) é integrante do conjunto de acordos assinados em 1994 que encerrou a Rodada Uruguai e criou a Organização Mundial do Comércio. Também chamado de Acordo Relativo aos Aspectos do Direito da Propriedade Intelectual Relacionados com o Comércio (ADPIC). Disponível em http://www.cultura.gov.br/site/wp-content/uploads/2008/02/ac_trips.pdf . Acesso em 12/04/11

${ }^{5}$ Prática de empresas multinacionais para a busca e investigação do conhecimento de povos tradicionais acerca do uso que fazem dos recursos disponíveis dentro do bioma que os cerca a fim de identificar as propriedades terapêuticas ou cosméticas destes para posterior extração e comercialização privada.

${ }^{6}$ Créditos de carbono ou Redução Certificada de Emissões (RCE) são certificados emitidos para uma pessoa ou empresa que reduziu a sua emissão de gases do efeito estufa (GEE). Por convenção, uma tonelada de dióxido de carbono $\left(\mathrm{CO}_{2}\right)$ corresponde a um crédito de carbono. Este crédito pode ser negociado no mercado internacional.
} 


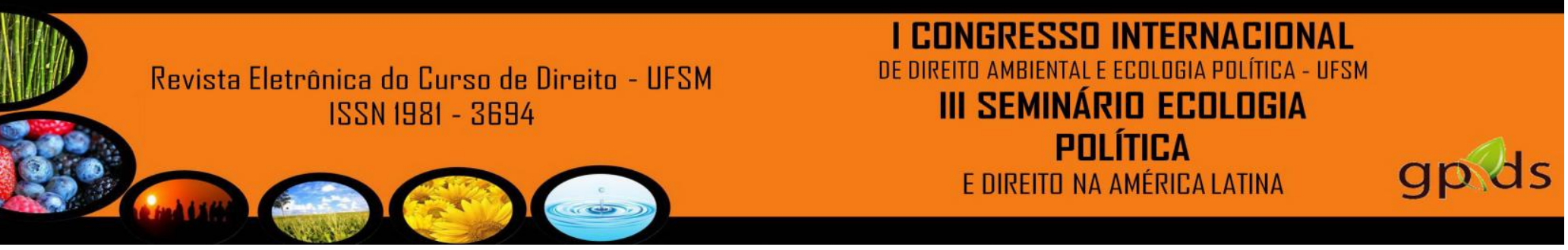

uma vida verdadeiramente sustentada. O próprio conceito de sustentabilidade foi desvirtuado e serve de amparo aos interesses de uma publicidade oportunista.

\subsection{Ecologização do capital}

Como já mencionado, a economia coisifica a natureza, dissocia o natural de sua complexidade ecológica e o transforma em matéria prima para a produção e maximização do capital. Afirma Leff (2006, p. 146-147) que quando a ecologia é abrangida pela economia,

[...] a natureza deixa de ser um objeto do processo de trabalho para ser codificada em termos de capital. Mas isso não devolve o ser à natureza, mas a transmuta em uma forma de capital - capital natural -, generalizando e ampliando as formas de valorização econômica da natureza. Nesse sentido, junto às formas de exploração intensiva, promove-se um uso "conservacionista" da natureza. A biodiversidade aparece não apenas como uma multiplicidade de formas de vida, mas como "reservas da natureza" territórios e habitat de diversidade biológica e cultural - que estão sendo valorizados por sua riqueza genética, seus recursos ecoturísticos e sua função como coletores de carbono.

A emergência desse capitalismo verde "maquia" o problema ambiental, apostando que a crise pode ser resolvida dentro das mesmas regras do jogo já estabelecidas. É uma espécie de resquício de crença no mercado, de persistência - por incrível que pareça - às disposições da Mão Invisível de Smith. Como menciona Altvater (1999, p. 139-140), "a possibilidade oligárquica (ou plutárquica) de comprar a natureza com dinheiro permanece em vigor." Aduz o mesmo autor (1999) que a estrutura neoliberal e o processo de globalização econômica enfraqueceram o potencial do Poder Público de regular a degradação ambiental, bem como todos os outros problemas (desemprego, pobreza, etc.) ligados à urbanização acelerada. A partir daí, a sociedade civil, representada pelas ONGS, movimentos sociais e ambientalistas, começam a se destacar como novas estruturas de governança política em nível local, nacional e até mesmo global. Nesse ponto, refere Altvater (idem, p. 147) que:

As estruturas de governança emergentes estão substituindo funções tradicionais do Estado, pelo menos nas áreas de política ambiental e social. Mas a importância desse tipo de governança é limitada. [...] O poder das organizações não governamentais também é limitado diante das companhias 
III SEMINÁRII ECOLDGIA

PDLÍTICA

E DIREITO NA AMÉRICA LATINA

privadas. A conciliação dos direitos humanos de segunda e terceira gerações e da participação democrática com a ordem econômica mundial requer maior regulamentação política, pautada nos princípios de justiça social, participação política e sustentabilidade ambiental. O funcionamento do mercado é bom apenas para a eficiência econômica em sentido estrito - mesmo assim, quando não falha.

Essa inépcia da dinâmica do mercado em lidar com a questão ambiental vem sendo demonstrada pelo desânimo relacionado às conferências internacionais ${ }^{7}$ sobre o tema, as quais resultaram praticamente infrutíferas em termos de comprometimento e direcionamento objetivo das ações estatais em termos de soluções.

Diante do fim inevitável do planeta, como também os limites da existência humana, representados pela Lei da Entropia ${ }^{8}$, o melhor que podem propor as políticas neoliberais de gerenciamento ambiental é retardar este esgotamento (LEFF, 2006), por meio dos programas de conservação da biodiversidade e dos biomas naturais, os novos - e entusiasmados - avanços na área da "tecnologia limpa", o controle das emissões de carbono (e as trocas de créditos e licenças), bem como a nova ética empresarial em torno da publicidade verde e do "consumo consciente". É cediço que esses programas são benéficos e representam consideráveis avanços em relação à possibilidade de um meio ambiente sustentável. No entanto, atenta Leff (2006, p.206) que

$\mathrm{Na}$ melhor das hipóteses, essas ações poderão desacelerar o ritmo de destruição ecológica para continuar marchando com ritmo mais lento, mas não menos firme, pelo caminho que conduz ao colapso ecológico e à morte entrópica do planeta.

A atual política da sustentabilidade sugere o ambiente como custo a ser gerenciado, a partir de uma perspectiva que vê a natureza como restrição ao crescimento econômico. Esse "respeito" ao meio ambiente natural representa uma nova ética que, ainda que bem intencionada, não reconhece a contribuição da natureza e os serviços ecológicos como potencial associativo ao processo econômico, dentro de uma possível racionalidade produtiva alternativa (LEFF, 2006).

\footnotetext{
7 Por exemplo, Copenhague 2010, bem como a Rio+20. Sobre o tema: Os desafios da "razão ambiental", de Pedro Cláudio Cunca Bocayuva, em Le Monde Diplomatique, edição Julho 2012, acesso em http://www.diplomatique.org.br/artigo.php?id=1215. No artigo, refere o autor que "É necessário elaborar uma crítica da "razão ambientalista" e repolitizar o tema."

${ }^{8}$ http://pt.wikipedia.org/wiki/Entropia
} 


\section{Reapropriação da natureza: semear soluções}

A possibilidade de ressignificação do ser no mundo, bem como de uma apropriação sustentável da natureza, requer, fundamentalmente, a libertação dos indivíduos (como cidadãos) dos paradigmas condicionados da Ciência Moderna. Essa superação possibilitaria uma visão de mundo sistêmico-complexa, onde não se vislumbra separação entre o ser humano e o ambiente que o cerca. "Em vez de tratar a teia da vida como mercadoria," menciona Capra (2003. p. 212), "respeitá-la-íamos como o próprio contexto em que se desenrola a nossa existência”.

O surgimento de um novo paradigma produtivo, dentro de uma economia sustentável, depende de uma visão onde os bens e serviços ambientais são entendidos como um potencial produtivo que considera tanto os limites naturais dos recursos, bem como as estratégias sociais que possam administrar os potenciais ecológicos da natureza (LEFF, 2006). Neste sentido, a melhor maneira de empregar estes potenciais de maneira sustentada é confiá-los aos que detém sobre eles um conhecimento profundo, muitas vezes milenar, e, principalmente, não meramente econômico: as comunidades tradicionais.

Sabe-se que os conhecimentos tradicionais, incluídos no processo produtivo, ainda que sem compensação aos detentores originários, maximizam a produtividade e o lucro ${ }^{9}$. Restaria incluí-los ao saber científico, a partir de uma perspectiva de complementaridade de saberes, de modo que não se limitassem à utilidade do mercado, mas que pudessem contribuir na preservação do ambiente, ao mesmo tempo em que servem de sustento aos seres vivos. Como afirma Leff (2006, p. 185):

Os sistemas vivos não estabelecem apenas um conjunto de condições que a economia deve respeitar e funcionam como umbrais da capacidade de carga dos ecossistemas. A natureza, como um conjunto de sistemas de suporte da

\footnotetext{
9 Segundo Vandana Shiva (2001, p.101): Dos 120 princípios ativos atualmente isolados na medicina moderna, $75 \%$ têm utilidades que foram identificadas pelos sistemas tradicionais. Menos de doze são sintetizados por modificações químicas simples; o resto é extraído diretamente de plantas e depois purificado. Diz-se que o uso do conhecimento tradicional aumenta a eficiência de reconhecer as propriedades medicinais de plantas em mais de $400 \%$.
} 
vida, potenciais ecológicos e de serviços ambientais, é condição fundamental para a existência de uma economia sustentável.

Portanto, a inclusão das comunidades tradicionais, por meio dos movimentos sociais que visem à apropriação dos processos produtivos fundados nos potenciais da natureza e da cultura, pode conduzir à criação de estratégias sustentáveis de gestão dos recursos naturais. Levar-se-ia em conta os princípios de autonomia cultural, equidade social e justiça ambiental, assimilando as condições da natureza, bem como seu "limite", na gestão produtiva da biodiversidade em escala local e no âmbito comunitário (LEFF, 2006).

\subsection{Educação Ambiental: (re)entender a natureza}

Antes que (e para que) novos sistemas de produção sejam concebidos, o homem, como afirma Araújo e Silva (p.142, 2007):

[...] deve assimilar novos valores que lhe propicie condições de desenvolver uma nova percepção sobre o mundo. De uma visão obsoleta e inadequada sobre a realidade, devemos partir para a construção de um outro mundo, mais saudável em termos ecológicos, o que significa mudança no modo de pensar a relação homem/natureza. [...] Essa mudança paradigmática deve atingir todas as áreas do conhecimento, num esforço interdisciplinar, permitindo a reconciliação do homem com a natureza.

É necessário que estes valores se integrem desde a educação básica nas escolas, até o nível superior, inclusive perpassando pelo ensino do Direito, onde se poderia pensar com mais profundidade a possibilidade de emancipação das comunidades tradicionais/saberes locais, a partir dos direitos de Propriedade Intelectual, bem como ao que tange os dilemas que envolvem o direito intergeracional.

Consiste como imprescindível para esse novo entendimento uma compreensão ampla dos sistemas vivos e seus padrões de organização. Durante mais de três bilhões de anos de evolução, como afirma Capra (2001, p. 231), “os ecossistemas do planeta têm se organizado de maneiras sutis e complexas, a fim de maximizar a sustentabilidade. Essa sabedoria da natureza é a essência da eco-alfabetização.” 
A consciência ecológica pode levar o cidadão a questionar, do mesmo modo, o seu estilo de vida (e, por conseguinte, de consumo) que a globalização econômica apresentou como o ideal. Como salientado por Smith (1998, p. 130-131):

A cidadania ecológica levará a espécie humana a uma reavaliação fundamental das suas capacidades para agir sobre o meio ambiente. A complexidade, a incerteza e a interconexão crescente de todas as coisas vivas, bem como os sistemas que sustentam a vida das mesmas, tornam a reavaliação das obrigações humanas ainda mais imperativas.

Aprender a (e com a) natureza pode ser o meio hábil na construção de sistemas produtivos sustentáveis. É necessário, como aduz ainda Capra (2001, p. 231), "revitalizar nossas comunidades - inclusive nossas comunidades educativas, comerciais e políticas - de modo que os princípios da ecologia se manifestem nelas como princípios de educação, de administração e de política." Em suma, precisamos aprender a aprender a complexidade ambiental (LEFF, 2003), para poder criar soluções e agir no mundo de forma consciente.

\section{CONSIDERAÇÕES FINAIS}

Como visto, a crise ambiental está ligada, antes mesmo de uma ação, a uma percepção de mundo. Quando essa percepção traz consigo a idéia antropocêntrica e limitada, ignorando as dinâmicas sutis de interação entre homem/ambiente, conduz-se a uma organização político-econômica que vai encontrar na natureza um limite. Deste modo, evidencia-se que a crise ecológica representa, essencialmente, uma crise do pensamento.

Quando abrimos nossas janelas e observamos o movimento solar durante o dia, podemos ter a sensação de que é o astro-rei que se movimenta, ainda que saibamos, racionalmente, que é a Terra que gira no movimento de rotação. Do mesmo modo, saber da crise ecológica não significa entender profundamente o processo de interação que a origina, muito menos agir de forma menos nociva ao ambiente que nos cerca. Ainda assim, podemos olhar o mundo com os mesmos olhos que já olhamos, mas com estruturas internas que vejam significados diferentes. 



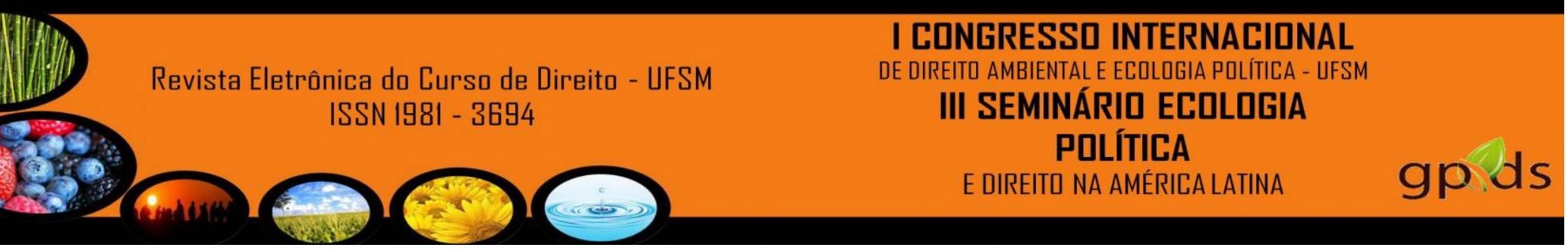

LEFF, ENRIQUE. Racionalidade Ambiental: a reapropriação social da natureza;

Tradução de Luís Carlos Cabral. Rio de Janeiro: Civilização Brasileira, 2006.

MATURANA, Humberto R.; VARELA, Francisco J. A árvore do conhecimento: as bases biológicas da compreensão humana. São Paulo: Athenas, 5ª ed. 2005.

SHIVA, Vandana. Monoculturas da mente: perspectivas da biodiversidade e da biotecnologia. São Paulo: Gaia, 2003. 